University of Nebraska - Lincoln

DigitalCommons@University of Nebraska - Lincoln

Faculty Publications, Department of Psychology

Psychology, Department of

March 1995

\title{
Memory Processes in Elderly Eyewitnesses: What We Know and What We Don't Know
}

Brian H. Bornstein

University of Nebraska-Lincoln, bbornstein2@unl.edu

Follow this and additional works at: https://digitalcommons.unl.edu/psychfacpub

Part of the Psychiatry and Psychology Commons

Bornstein, Brian H., "Memory Processes in Elderly Eyewitnesses: What We Know and What We Don't Know" (1995). Faculty Publications, Department of Psychology. 200.

https://digitalcommons.unl.edu/psychfacpub/200

This Article is brought to you for free and open access by the Psychology, Department of at DigitalCommons@University of Nebraska - Lincoln. It has been accepted for inclusion in Faculty Publications, Department of Psychology by an authorized administrator of DigitalCommons@University of Nebraska - Lincoln. 


\title{
Memory Processes in Elderly Eyewitnesses: What We Know and What We Don't Know
}

\author{
Brian H. Bornstein, Ph. D.
}

\begin{abstract}
Research is reviewed on the memory abilities of elderly eyewitnesses. Two major issues are addressed: First, how credible are elderly witnesses? Second, how accurate are they? Despite negative stereotypes regarding elderly eyewitnesses, they do not necessarily lack credibility at trial. In terms of their memory performance, older witnesses are as accurate as young adults in many respects, but they are particularly vulnerable to misleading information that is presented after the witnessed event. Furthermore, their performance varies depending on the type of information that is sought and the manner in which their memory is assessed. Recommendations are made for improving the reliability of testimony that is offered by elderly eyewitnesses.
\end{abstract}

In recent years there has been growing interest in the eyewitness memory of children, which has resulted in the publication of numerous articles and several books on the subject (Ceci, Ross, \& Toglia, 1989; Ceci, Toglia, \& Ross, 1987; Dent \& Flin, 1992; Goodman \& Bottoms, 1993; Perry \& Wrightsman, 1991). Relatively scant attention has been paid, however, to issues concerning the memory capabilities of elderly eyewitnesses. This disparity is probably due, at least in part, to the important role of children's testimony in cases involving physical or sexual abuse (e.g., Goodman, Aman, \& Hirschman, 1987); yet elderly adults may also frequently be crime victims. Crimes against the elderly are increasing, as the crime rate in general increases and the elderly segment of the population becomes larger (Cunningham, 1976; Hoyer, 1979). In addition, the fact that older individuals are staying active longer increases the probability that they will be bystander witnesses to various crimes. Reliable statistics do not exist on whether children or elderly adults are, overall, relatively more likely to be crime victims. However, children are probably more likely to be victims of some crimes, such as sexual abuse, while the elderly are especially likely to be victims of certain other types of crimes, such as fraud, personal larceny, and burglary (Cunningham, 1976; Dussich \& Eichman, 1976; Hoyer, 1979).

I am grateful to A. C. Emler and two anonymous reviewers for helpful comments on the manuscript. 
It has been well established that certain cognitive functions, including memory, tend to decline in normal aging (Craik \& Trehub, 1982; Salthouse, 1991). ${ }^{1}$ Thus, just as it is necessary to understand the impact of children's general memory processes on their testimonial competence, it is important to know what effect, if any, the aging process might have on the testimony offered by elderly witnesses. The present paper addresses this issue by focusing on two questions: First, how credible are elderly witnesses? The impact of any eyewitness's testimony is influenced greatly by jurors' perceptions of his or her reliability. Jurors' stereotypes about children's cognitive limitations lead them to evaluate child witnesses, especially very young ones, as less credible than adults (Goodman, Golding, Helgeson, Haith, \& Michelli, 1987; Yarmey \& Jones, 1983). To the extent that jurors are aware of some of the cognitive deficits associated with old age, elderly witnesses' reports might likewise be weighed less heavily than those of young adults.

Second, how accurate is older subjects' eyewitness memory? Jurors' ability to estimate the accuracy of adult eyewitnesses is poor (Lindsay, Wells, \& Rumpel, 1981); hence, elderly witnesses might be perceived as unreliable, while their actual memory performance in eyewitness situations is in fact quite good. Elderly subjects' accuracy can be investigated directly, by comparing older and younger adults' performance in eyewitness situations, and indirectly, by examining the effect of age on performance in tasks that are highly relevant to eyewitness memory such as face recognition. Finally, one can evaluate accuracy by considering whether factors having a negative effect on eyewitness memory in general, such as misleading suggestions, might have an especially pronounced influence on elderly subjects. After reviewing research on age effects on eyewitness accuracy, the paper concludes with recommendations for improving the memory performance of elderly witnesses.

\section{CREDIBILITY}

Ross, Dunning, Toglia, and Ceci (1990, Experiments 1 and 2) addressed mock jurors' perceptions of an eyewitness as a function of the witness's age. Subjects were shown a videotape of a simulated drug trial, in which the prosecution's key witness was portrayed by an 8-, 21-, or 74-year-old male. Subsequently, they rated the key witness's credibility along a number of dimensions and judged the degree of the defendant's guilt/innocence. The witness's age had no effect on subjects' estimates of the defendant's guilt; yet, contrary to expectation, both the child and the elderly eyewitness were perceived as more credible overall than the young adult witness. Specifically, the elderly witness was viewed as more accurate, more likely to be telling the truth, more intelligent, and more trustworthy, compared to the young adult witness.

This result is particularly surprising in light of Ross et al. 's (1990, Experiment 3) finding that subjects held a negative stereotype about elderly adults' eyewitness capabili-

\footnotetext{
${ }^{1}$ The definition of "normal" aging is highly variable. Most commonly, it is operationalized as the study of adults who are in good health (i.e., non-pathological) and over age 60, though the age range varies (Salthouse, 1991). Cognitive deficits mayor may not be associated with physical (i.e., neurological) health problems. Salthouse (1991) points out that such cognitive deficits may be associated with aging without being inevitably caused by it.
} 
ties in general. Subjects (who were college undergraduates) viewed the average 74-yearold as having a less accurate memory than the average 21-year-old, as well as being more susceptible to misleading questions. Furthermore, although the elderly witness was perceived as somewhat more honest, they said that they would give an elderly witness's testimony less weight, and one-third of the subjects believed that at a certain age, people become too old to be trusted as witnesses (the average estimated "age of incompetency" was 75. 3 years). Interestingly, elderly subjects themselves are even more likely than college students - as well as than lawyers, judges, and other randomly selected potential jurorsto hold a negative stereotype about elderly witnesses' ability to give accurate testimony (Yarmey, 1982).

Thus, elderly witnesses are perceived as less credible than young adults in general, but this stereotype will not inevitably affect how a particular elderly eyewitness is perceived at trial. An analogous phenomenon occurs with child witnesses, who despite being stereotyped as less reliable than adults may come across in court as equally (and sometimes more) credible (Ross et al., 1990; Wells, Turtle, \& Luus, 1989). Ross et al. (1990) explain this discrepancy between a witness's perceived and actual credibility in terms of a "contrast effect," whereby case-specific behavior that is inconsistent with a stereotype-e.g., an elderly witness who is confident and self-assured - can actually enhance the witness's credibility.

In addition to the influence of stereotypic expectations, a witness's credibility can be affected by the aspect of credibility that is emphasized at trial. Leippe and Romanczyk (1987) distinguish between the "expertise" component of credibility-i.e., one's ability to remember - and the "honesty" component. Children are perceived as low in expertise, but high in honesty (Leippe \& Romanczyk, 1987). They are consequently seen as less credible than adults when the aspect of expertise is most salient, but more credible when the witness's honesty is especially relevant (Goodman, Bottoms, Herscovici, \& Shaver, 1989; Leippe \& Romanczyk, 1987).

Elderly eyewitnesses are perceived similarly, in that they are viewed as honest yet having faulty memories (Ross et al., 1990; Yarmey, 1984; Yarmey \& Jones, 1983). In a trial where the witness's honesty is the primary component of his or her credibility, as in Ross et al.'s (1990) simulated drug trial, an elderly witness would have high credibility. On the other hand, if the witness's ability to remember events and provide verbal descriptions is emphasized, the elderly eyewitness is likely to be less credible than a younger adult. Attorneys interested in raising the credibility of an elderly witness would do well to attend to these separate aspects of credibility and, where possible, stress the honesty component while minimizing the importance of memory expertise. Future research is needed that explicitly compares the credibility of elderly eyewitnesses in trials emphasizing these different aspects of witness credibility, but past research clearly suggests that elderly adults are not necessarily perceived as lacking credibility. Ross et al. (1990) conclude that, concerning both children and older adults, "witness age has no uniform influence on juror perceptions of credibility (p. 18)."

\section{AGE EFFECTS ON EYEWITNESS ACCURACY}

Research focusing on the accuracy of elderly eyewitnesses has addressed two separate components of eyewitness memory: the ability of eyewitnesses to describe details of the 
event, and their ability to recognize the crime's perpetrator (Yarmey \& Kent, 1980). The importance of the latter component is obvious; yet a variety of details may also be highly relevant at trial, such as the color of a traffic light, what someone said, the number of gunshots fired, the color of the perpetrator's clothing, and so forth.

Elderly witnesses' memory for detail depends in large part on how their memory is tested. List (1986) found that compared to college students, older subjects (mean age = 67. 6) who viewed videotaped shoplifting scenes remembered fewer details on a free recall measure, and what they did recall was less accurate. Older subjects are also less confident in their recall performance (Yarmey, 1993). Elderly subjects are similarly disadvantaged when their memory for details is assessed with a recognition test employing a multiple-choice technique (e.g., "The assailant wore: (a) dark brown pants; (b) light blue pants; (c) blue jeans; (d) light brown pants"; taken from Yarmey \& Kent, 1980). Their performance can be as good as younger subjects if a yes-no recognition test (e.g., "The assailant's pants were dark brown-yes or no?") is used (List, 1986), though they sometimes perform worse than young adults using this format as well (Loftus, Levidow, \& Duensing, 1992).

The effect of these different testing techniques reflects the common observation that as people age, they do especially poorly on memory tasks that require self-initiated effort and the spontaneous use of retrieval strategies, such as free recall (e.g., Craik, 1977). Elderly subjects may be able to use the types of retrieval strategies that recall tests require but lack the motivation to do so; their performance consequently suffers disproportionately (Perlmuter \& Monty, 1989). On recognition tests, on the other hand, which are less demanding in this respect because they provide more retrieval cues, age differences are significantly reduced (Craik, 1977; Craik \& McDowd, 1987). The inclusion of distractors in a multiple-choice recognition test would tend to make it harder than a yes-no recognition test, which could explain why Yarmey and Kent (1980) observed an age-related impairment on recognition, while list (1986) did not. Thus, elderly witnesses are not necessarily worse than younger adults at remembering details of a crime; this finding has practical implications for dealing with elderly witnesses, which are discussed below.

Perhaps the most important task facing an eyewitness is the identification of the perpetrator. As with memory for details, age has no uniform effect on identification accuracy. ${ }^{2}$ O'Rourke, Penrod, Cutler, and Stuve (1989) found that age was negatively correlated with accuracy among subjects who saw a short videotape of a robbery; however, only twelve of 120 subjects were over age 60 , so this result should be interpreted with a degree of caution. Yarmey and Kent (1980), on the other hand, included age as a grouping variable and found that older subjects (mean age $=73.1$ ) were just as accurate as young adults (mean age $=18.6)$ at recognizing the assailant in a simulated assault. The only age difference in subjects' identification capacity was for identifying a bystander to the event, at which older subjects performed worse. Although it is clearly less important to be able to identify a bystander correctly than the perpetrator, older subjects' inferior memory for bystand-

\footnotetext{
${ }^{2}$ Eye witness identification usually involves visual recognition of the criminal, but there are cases in which recognition is based on auditory cues. Although "earwitness" identification is beyond the scope of this paper, it should be noted that there is some evidence that it worsens with age (Bull \& Clifford, 1984).
} 
ers can make them more likely to identify a bystander as the perpetrator (Yarmey, 1984), a potential error with very undesirable consequences.

The subtle nature of age differences in identification accuracy is also shown in research on recognizing faces that is done outside the eyewitness paradigm. The basic faceidentification paradigm is similar to that used in eyewitness lineups in that subjects are shown a face (or more often, a series of faces); then after some delay interval, they are presented those faces as well as previously unseen faces (or "foils"), and asked whether each face is old or new. This procedure differs from eyewitness research most notably in that the target face is presented by itself and not in the context of a complex event like a crime. Elderly subjects may be worse than or as good as young adults on such tasks, depending on how accuracy is measured. The primary measures of accuracy are hits - correctly identifying old faces - and false alarms, or saying that a new face was seen previously (Shapiro \& Penrod, 1986). Variables that strongly influence one measure do not necessarily influence the other (Shapiro \& Penrod, 1986), a lack of correlation which holds true for the variable of age. Older subjects make the same number of hits as young adults, but they make more false alarms (Bartlett \& Leslie, 1986; Ferris, Crook, Clark, McCarthy, \& Rae, 1980; Smith \& Winograd, 1978). Furthermore, they are less confident than young adults when they do correctly reject foils (Yarmey, 1984; Yarmey \& Kent, 1980). Older subjects' greater difficulty at rejecting foils in an identification task is consistent with their greater tendency to select false information when recognizing details of the event (Yarmey \& Kent, 1980).

This age difference in false alarms is eliminated, however, if subjects are shown multiple views of the original face (Bartlett \& Leslie, 1986). Bartlett and Leslie (1986) point out that presenting subjects with multiple views is a more realistic experimental manipulation: when a person experiences a face in one's natural environment (whether or not it is in the context of witnessing a crime), one typically views it from more than one angle and sees it adopt various expressions. In this more naturalistic situation, older subjects (mean age $=74.2$ ) were just as accurate as high school seniors at recognizing previously seen faces, in terms of both hits and false alarms. ${ }^{3}$ Although it is necessary, before drawing any definitive conclusions, to conduct a similar experiment with subjects who witness a complex event like a crime, these results clearly suggest that identification accuracy does not inevitably deteriorate with age.

In summary, elderly eyewitnesses' memory performance depends heavily on how their memory is assessed. In remembering details of a crime, they tend to recall less than younger witnesses but demonstrate little, if any, deficiency at recognizing details of the event. Older subjects' ability to identify a suspect's face also shows little impairment. They are more likely than younger adults to identify a bystander or novel stimulus as the culprit, but even this effect may be mitigated if they are provided with a rich, multiperspective view of the suspect's face. Interestingly, mock jurors are sensitive to elderly witnesses' greater ability to recognize suspects than to recall verbal details about a crime (Yarmey \& Jones, 1983).

\footnotetext{
${ }^{3}$ O'Rourke. et al. (1989) found that a similar manipulation that included multiple perspectives during an eyewitness lineup — e.g., by showing suspects' gait and posture-did not improve identification. regardless of subjects' age. This result suggests that the benefit of multiple perspectives comes from inducing deeper processing during encoding, when the target stimulus is first seen (as in Bartlett \& Leslie, 1986), and not at retrieval.
} 


\section{THE EFFECT OF AGE ON FACTORS THAT IMPAIR EYEWITNESS MEMORY}

Regardless of an eyewitness's age, the accuracy of his or her memory can be affected by a variety of factors having to do with the witness, the suspect, or the event itself (Deffenbacher, 1991). For example, memory is impaired when the witness has relatively little opportunity to observe the perpetrator (Deffenbacher, 1991), when the witness's race is different from the suspect's (Bothwell, Brigham, \& Malpass, 1989; Shapiro \& Penrod, 1986), or when the witness is given misleading information after the event has occurred (Loftus, 1979; Loftus, Miller, \& Burns, 1978). ${ }^{4}$

It seems fairly obvious that a witness's ability to identify the suspect will be affected by his or her length of exposure to the suspect, particularly to the suspect's face; and indeed, time spent looking at the perpetrator correlates positively with witness accuracy (Deffenbacher, 1991). Processing of visual and auditory information are abilities that deteriorate with age (e.g., Stine, Wingfield, \& Poon, 1989). Thus, older adults are likely to be at a particular disadvantage in witnessing crimes, which are often chaotic and contain a large number of competing visual and auditory stimuli.

Any aspect of the event that interferes with the witness's ability to observe the perpetrator will have a negative effect on the witness's subsequent memory. For example, the salient presence of a weapon tends to draw the witness's attention to the weapon, consequently impairing recognition of the criminal's face (Loftus, Loftus, \& Messo, 1987). The "weapon focus" phenomenon impairs identification accuracy regardless of the witness's age (O'Rourke et al., 1989). Importantly, however, its deleterious effect does not become greater as the witness's age increases (O'Rourke et al., 1989).

As discussed above, older adults perform worse than college-age subjects when a high demand is placed on attention to detail, while they are less disadvantaged at overall face recognition (Bartlett \& Leslie, 1986; Yarmey \& Kent, 1980). One explanation for people's greater ability to recognize members of their own race than other races is that they attend less to detailed features in processing other-race faces (Bothwell et al., 1989; Shapiro \& Penrod, 1986). Thus, one might expect older subjects to show a stronger own-race bias than younger subjects. Brigham and Williamson (1979) found that, like college-age subjects, elderly subjects were better at recognizing own-race than other-race faces; however, they did not include age as a variable in their experiment, so it is unknown whether this tendency is more pronounced in elderly witnesses.

Loftus and her colleagues have demonstrated that subjects' reported memory for an event is influenced by information concerning the event that is suggested to them after the event has taken place. (e.g., Loftus, 1979; 1992; Loftus et al., 1978). For example, sub-

\footnotetext{
${ }^{4}$ This is only a small subset of the variables that have been shown to affect eyewitness memory (for broader reviews, see Deffenbacher, 1991; Loftus, 1979; Ross, Read, \& Toglia, 1994; Wells \& Loftus, 1984). I have selected these specific factors for further discussion because of the possibility that their effect is moderated by the variable of witness age.
} 
jects who witnessed a car stopping at a yield sign, and who were subsequently asked, "Did another car pass the red Datsun while it was stopped at the stop sign? (emphasis added) " were less likely to identify the yield sign (correctly) as what they originally saw than subjects who were not misled (Loftus et al., 1978). Research has shown that children may be particularly susceptible to such suggestions (Ceci \& Bruck, 1993; Doris, 1991). There are reasons to suspect that older adults would be highly suggestible as well.

Lindsay (1990; Lindsay \& Johnson, 1989) has reconceptualized the misinformation effect in terms of "source monitoring. "Source monitoring refers to judgments about the origin, or source, of information, as opposed to remembering the information itself Johnson, Hashtroudi, \& Lindsay, 1993). For example, one might recall that O. J. Simpson was charged with his ex-wife's murder without being able to remember where one originally acquired that information; was it heard on the radio, watched on television, read in the newspaper, or communicated by a friend? According to Lindsay (1990), the misinformation effect reflects a failure of source monitoring. Specifically, an eyewitness acquires information about an event from two sources: by observing the event itself, and from subsequent suggestion. When the witness then falsely remembers a piece of information as part of the event, rather than as a suggestion, he or she has committed a source monitoring error, which impairs the ability to remember the original event details correctly.

The source monitoring approach is particularly relevant to studying memory in elderly eyewitnesses because of the effect of aging on this specific type of memory task. Compared to young adults, elderly subjects have difficulty remembering the source of information (e.g., Hashtroudi, Johnson, \& Chrosniak, 1989; Schacter, Kaszniak, Kihlstrom, \& Valdiserri, 1991); however, their memory for the information itself is unimpaired (McIntyre \& Craik, 1987). Cohen and Faulkner (1989, Experiment 2) applied these findings to an eyewitness situation, by showing subjects a film of a kidnapping, and then presenting them with a narrative containing misleading details. When tested on their memory of the film, elderly subjects (mean age $=$ 70 ) were significantly more likely than younger subjects (mean age $=35$ ) to have been misled by suggestive information that was in the narrative. Loftus et al. (1992) also found a tendency for elderly subjects (over age 65) to be more suggestible than younger adults when remembering details of a videotaped crime. Thus, older adults are more susceptible than young adults to misleading suggestions, and this disparity appears to be due, at least in part, to an impaired ability to discriminate between different sources of information.

There is not a great deal of evidence regarding the interaction between age and factors that influence eyewitness memory, but what evidence there is suggests that age may exacerbate the negative influence of some variables. Consistent with research showing that aging is associated with source monitoring deficits, the effect of misleading suggestions becomes greater in elderly subjects. Although this is true when the misinformation concerns details of the witnessed event (Cohen \& Faulkner, 1989; Loftus et al., 1992), it is not clear whether it would hold for misinformation concerning face recognition, where elderly subjects show little, if any, impairment (Yarmey \& Kent, 1980). Research is needed that tests whether a misleading face presented after the event, or even 
a misleading description of a perpetrator's face, would have differential effects on recognizing the perpetrator depending on subjects' age. Oilier factors, such as the witness's opportunity to observe me crime, weapon focus, and cross-racial identification, affect the elderly in the same manner as younger subjects. A greater effect of these variables in elderly witnesses has not been demonstrated; however, inasmuch as the average elderly eyewitness could be expected to make poorer observations, owing simply to inferior sensory capabilities, these factors might also become more problematic as a witness's age increases.

\section{MEANS OF IMPROVING ELDERLY EYEWITNESSES' MEMORY}

Based on these findings, a number of recommendations can be made for improving me accuracy of elderly eyewitnesses. An abundance of research shows that older subjects perform more like young adults when fewer demands are placed on their retrieval processes, indicating mat they often know more than they can say (e.g., Craik, 1977). When asking an elderly witness to remember details of a crime, attempts should be made to ask precise questions and emphasize recognition memory, as opposed to recall. Of course, those questioning elderly witnesses would have to make a careful effort not to present recognition questions in a leading manner. A reasonable and effective compromise would be to begin with unstructured, free recall ("Tell me everything you can remember"), then move to specific questions ("What color was the perpetrator's shirt?"), and finish with a series of yes-no recognition questions ("Was his shirt blue? red?" etc.).

When elderly witnesses are asked to identify a criminal suspect, there is a larger risk than with younger witnesses that they will pick an innocent person from the lineup (Bartlett, 1993; Ferris et al., 1980; Smith \& Winograd, 1978). The false alarm problem could be addressed in two different ways: by changing the lineup procedure, or by facilitating the retrieval process. With elderly witnesses, police should emphasize even more than usual the degree of certainty that is required to identify a suspect from a lineup; this procedure is analogous to raising one's criterion in a signal-detection task, which reduces me number of false alarms (cf. Shapiro \& Penrod, 1986). In addition, me lineup could be presented one member at a time, rather than simultaneously. Young adult witnesses who were asked to make sequential yes-no judgments for each member of a lineup made fewer false alarms than when the standard procedure was used, in which they attempted to identify the suspect among several individuals presented simultaneously (Lindsay \& Wells, 1985). This variation is analogous to using a yes/no recognition test instead of a multiplechoice test with several distractors, which appears to minimize age differences in memory for details (compare List, 1986, to Yarmey \& Kent, 1980). As elderly eyewitnesses are especially prone to making false identifications, sequential presentation with these witnesses should prove particularly helpful.

Bartlett (1993) argues that elderly subjects' greater tendency to make false alarms results from a deficit in recollecting the context in which a face initially appeared. Thus, a 
second approach to alleviating the problem would be to reinstate the context during retrieval by instructing the elderly witness to imagine the scene of the crime. This technique is part of the "guided cognitive interview" procedure developed by Geiselman, Fisher, MacKinnon, and Holland (1985), which also has witnesses adopt different temporal orders and perceptual perspectives in remembering a crime. These mnemonic techniques increase the amount of detail information that young adult witnesses are able to remember (Fisher, Geiselman, \& Amador, 1989; Geiselman et al., 1985). Because they provide additional retrieval cues - something older adults are less proficient at doing on their own (Craik, 1977) — these techniques ought to improve elderly witnesses' memory for details as well. Consistent with Bartlett's (1993) approach, the guided interview has been shown to improve the identification accuracy of elderly, as well as young adult,. eyewitnesses (O’Rourke et al., 1989).

Using a somewhat related procedure, Bekerian and Bowers (1983) have demonstrated that eyewitness memory is improved by asking the witness questions about the event that adhere to a chronological sequence, rather than jumping around in time. In particular, this questioning technique reduces the effect of misinformation that is presented after the witnessed event. Alternatively, the misinformation effect can be reduced by testing eyewitness memory with a source monitoring procedure, rather than a standard recognition test. Lindsay and Johnson (1989) have demonstrated that misled subjects who were instructed to discriminate between sources (i.e., "Did this information come from the witnessed event or the post-event narrative?") made fewer errors than subjects who took a yes/no recognition test (i.e., "Was this information in the witnessed event?").

Neither Bekerian and Bowers' (1983) nor Lindsay and Johnson's (1989) technique has been used with elderly eyewitnesses; but in light of older individuals' heightened susceptibility to misleading suggestions (Cohen \& Faulkner, 1989; Loftus et al., 1992) and general source monitoring deficits Johnson et al., 1993), these methods should be at least as effective as with younger subjects. Other means of reducing the effect of misleading information that have been demonstrated in young adult subjects, and might work equally well with elderly witnesses, include warning the witness about the possibility of encountering misinformation (Greene, Flynn, \& Loftus, 1982) and having the witness make a public statement prior to learning any subsequent information (Loftus, 1979).

\section{SUMMARY: WHAT WE KNOW, WHAT WE DON'T KNOW, AND WHAT WE NEED TO KNOW}

In the 10 years since Yarmey (1984) noted the paucity of research on eyewitness memory in the elderly, a number of findings have been added to the literature, though the topic is still vastly underresearched relative to children's testimony. Despite people's generally low expectations regarding- the quality of testimony offered by elderly witnesses (Ross et al., 1990, Experiment 3; Yarmey \& Jones, 1983), their testimony does not necessarily lack credibility (Ross et al., 1990, Experiments 1 and 2). It is likely that elderly witnesses are perceived favorably in trial situations that place a high premium on honesty, but unfavorably when their ability to remember is emphasized. 
With regard to elderly witnesses' memorial capacities, there is little evidence to suggest that eyewitness abilities deteriorate substantially with age. Older eyewitnesses are able to remember details of an event as well as younger witnesses if they are asked to recognize rather than freely recall them (List, 1986). They do show a tendency to make more false identifications in face recognition (Bartlett, 1993; Smith \& Winograd, 1978), but this tendency may be a consequence of using impoverished and unrealistic target stimuli (Bartlett \& Leslie, 1986). Furthermore, it can be offset by providing more contextual cues at retrieval (Bartlett, 1993; O’Rourke et al., 1989).

Variables that negatively affect young adults' eyewitness memory, such as weapon focus and cross-race identification, affect older subjects as well, but not to a demonstrably greater extent (Brigham \& Williamson, 1979; O’Rourke et al., 1989). It is possible that other factors influencing eyewitness reliability, such as arousal, physical distinctiveness of the suspect, or witness gender (Deffenbacher, 1991; Wells \& Loftus, 1984) would have a disproportionate effect on elderly witnesses, but systematic research on the relationship of age to those factors remains to be done (though see Loftus et al., 1992, and Yarmey, 1993, on gender differences as a function of age).

The only factor which has been reliably shown to affect elderly eyewitnesses more than young adults is post-event misinformation (Cohen \& Faulkner, 1989; Loftus, et al., 1992). This finding reflects older adults' general difficulty in performing source monitoring tasks (e.g., Hashtroudi et al., 1989). Research is needed to test the hypothesis that techniques that can be used successfully to minimize the misinformation effect in young adults (e.g., Bekerian \& Bowers, 1983; Lindsay \& Johnson, 1989) would likewise be effective with elderly subjects.

In summary, elderly eyewitnesses are disadvantaged less in what they can remember than in how they respond to certain types of testing procedures. Previous research suggests that their retrieval of information could be enhanced by emphasizing recognition rather than recall of both faces and event details, and by otherwise providing contextual retrieval cues. Future research is called for on additional techniques that can be used to optimize the recollections of elderly witnesses and to minimize pitfalls to which they are particularly susceptible, such as false positive identifications and the effect of misinformation. As such techniques are developed, elderly eyewitnesses should be able to demonstrate a high level of reliability and to make significant contributions to criminal investigations and trials.

\section{References}

Bartlett, J. C. (1993). Limits on losses in face recognition. In J. Cerella, J. Rybash, W. Hoyer, \& M. Commons (Eds.), Adult information processing: Limits on loss (pp. 351-379). San Diego: Academic Press.

Bartlett, J. C., \& Leslie, J. E. (1986). Aging and memory for faces versus single views of faces. Memory \& Cognition, 14, 371-381.

Bekerian, D., \& Bowers, J. (1983). Eyewitness testimony: Were we misled? Journal of Experimental Psychology, 9, 139-145.

Bothwell, R., Brigham, J., \& Malpass, R. (1989). Cross-racial identification. Personality and Social Psychology Bulletin, 15, 19-25.

Brigham, J. C., \& Williamson, N. L (1979). Cross-racial recognition and age: When you're over 60, do they still "all look alike?". Personality and Social psychology Bulletin, 5, 218-222.

Bull, R, \& Clifford, B. R (1984). Earwitness voice recognition accuracy. In G. L Well \& E. F. Loftus (Eds.), Eyewitness testimony: psychological perspectives (pp. 92-123). Cambridge, MA: Cambridge University Press. 
Ceci, S. J., \& Bruck, M. (1993). Suggestibility of the child witness: A historical review and synthesis. Psychological Bulletin, 113, 403--439.

Ceci, S. J., Ross, D., \& Toglia, M. P. (Eds.). (1989). Perspectives on children's testimony. New York: Springer-Verlag.

Ceci, S. J., Toglia, M. P., \& Ross, D. (Eds.). (1987). Children's eyewitness testimony. New York: Springer-Verlag.

Cohen, G., \& Faulkner, D. (1989). Age differences in source forgetting: Effects on reality monitoring and on eyewitness testimony. Psychology and Aging, 4, 10-17.

Craik, F. I. (1977). Age differences in human memory. In J. Birren \& K. Schaie (Eds.), Handbook of the psychology of aging (pp. 384-420). New York: Van Nostrand Reinhold.

Craik, F. I., \& McDowd, J. (1987). Age differences in recall and recognition. Journal of Experimental Psychology: Learning, Memory and Cognition, 13, 474-479.

Craik, F. I., \& Trehub, S. (Eds.). (1982). Aging and cognitive processes. New York: Plenum.

Cunningham, C. L (1976). Pattern and effect of crime against the aging: The Kansas City study. In J. Goldsmith \& S. S. Goldsmith (Eds.), Crime and the elderly (pp. 31-50). Lexington, MA: Lexington Books.

Deffenbacher, K A. (1991). A maturing of research on the behaviour of eyewitnesses. Applied Cognitive Psychology, 5, 377-402.

Dent, R, \& Flin, R (Eds.). (1992). Children as witnesses. Chichester: Wiley \& Sons.

Doris, J. (Ed.). (1991). Suggestibility of children's recollections. Washington, DC: American Psychological Association.

Dussich, J. P., \& Eichman. C. J. (1976). The elderly victim: Vulnerability to me criminal act. In J. Goldsmith \& S. S. Goldsmith (Eds.), Crime and the elderly (pp. 91-98). Lexington, MA: Lexington Books.

Ferris, S. B., Crook, T., Clark, E., McCarthy, M., \& Rae, D. (1980). Facial recognition memory deficits in normal aging and senile dementia. Journal of Gerontology, 35, 707-714.

Fisher, R, Geiselman, R, \& Amador, M. (1989). Field test of the cognitive interview: Enhancing the recollection of actual victims and witnesses of crime. Journal of Applied psychology, 74, 722-727.

Geiselman, R, Fisher, R., MacKinnon, D., \& Holland, B. (1985). Eyewitness memory enhancement in the police interview: Cognitive retrieval mnemonics versus hypnosis. Journal of Applied Psychology, 70, 401-412.

Goodman, G. S., Aman, C., \& Hirschman, J. (1987). Child sexual and physical abuse: Children's testimony. In S. Ceci, M. Toglia, \& D. Ross (Eds.), Children's eyewitness testimony (pp. 1-23). New York: Springer-Verlag.

Goodman, G. S., \& Bottoms, B. L. (Eds.). (1993). Child victims. child witnesses: Understanding and improving testimony. New York: Guilford Press.

Goodman, G. S., Bottoms, B. L., Herscovici, B., \& Shaver, P. (1989). Determinants of the child victim's perceived credibility. In S. Ceci, D. Ross \& M. Toglia (Eds.), Perspectives on the child witness (pp. 122). New York: Springer-Verlag.

Goodman, G. S., Golding, J., Helgeson, V., Haith, M., \& Michelli, J. (1987). When a child takes the stand: Jurors' perceptions of children's eyewitness testimony. Law and Human Behavior, 11, 27-40.

Greene, E., Flynn, M. S., \& Loftus. E. F. (1982). Inducing resistance to misleading information. Journal of Verbal Learning and Verbal Behavior, 21, 207-219.

Hashtroudi, S., Johnson, M. K, \& Chrosniak, L. D. (1989). Aging and source monitoring. Psychology and Aging, 4, 106-112.

Hoyer, W. (1979). The elderly: Who are they? In A. Goldstein, W. Hoyer, \& P. Monti (Eds.), Police and the elderly (pp. 1-14). New York: Pergamon Press.

Johnson, M. K, Hashtroudi, S., \& Lindsay, D. S. (1993). Source monitoring. Psychological Bulletin, 114, 3-28.

Leippe, M. R., \& Romanczyk, A. (1987). Children on the witness stand: A communication/persuasion analysis of jurors' reactions to child witnesses. In S. Ceci, M. Toglia, \& D. Ross (Eds.), Children's eyewitness memory (pp. 155-177). New York: Springer-Verlag.

Lindsay, D. (1990). Misleading suggestions can impair eyewitnesses' ability to remember event details. Journal of Experimental Psychology: Learning, Memory, and Cognition, 16, 1077-1083.

Lindsay, D., \& Johnson, M. K (1989). The eyewitness suggestibility effect and memory for source. Memory \& Cognition, 17, 349-358. 
Lindsay, R, \& Wells, G. L (1985). Improving eyewitness identifications from lineups: Simultaneous versus sequential lineup presentation. Journal of Applied Psychology, 70, 556-564.

Lindsay, R., Wells, G. L., \& Rumpel, C. (1981). Can people detect eyewitness identification accuracy within and across situations? Journal of Applied Psychology, 66, 79-89.

List, J. A. G 986). Age and schematic differences in the reliability of eyewitness testimony. Developmental Psychology, 22, 50-57.

Loftus, E. F. (1979). Eyewitness testimony. Cambridge, MA: Harvard University Press.

Loftus, E. F. (1992). When a lie becomes memory's truth: Memory distortion after exposure to misinformation. Current Directions in Psychological Science, 1, 121-123.

Loftus, E. F., Levidow, B., \& Duensing, S. (1992). Who remembers best? Individual differences in memory for events that occurred in a science museum. Applied Cognitive Psychology, 6, 93-107.

Loftus, E. F., Loftus, G. R., \& Messo, J. (1987). Some facts about “weapon focus." Law and Human Behavior, 11, 55-62.

Loftus, E. F., Miller, D., \& Burns, H. (1978). Semantic integration of verbal information into a visual memory. Journal of Experimental Psychology: Human Learning and Memory, 4, 19-31.

McIntyre, J. S., \& Craik, F. I. (1987). Age differences in memory for item and source information. Canadian Journal of Psychology, 41, 175-192.

O’Rourke, T., Penrod, S., Curler, B., \& Stuve, T. (1989). The external validity of eyewitness identification research: Generalizing across subject populations. Law and Human Behavior, 13, 385-395.

Perlmuter, L. C., \& Monty, R. A. (1989). Motivation and aging. In L. W. Poon, D. C. Rubin, \& B. A. Wilson (Eds.), Everyday cognition in adulthood and late life (pp. 373-393). Cambridge, MA: Cambridge University Press.

Perry, N. W., \& Wrightsman, L. S. (1991). The child witness: Legal issues and dilemmas. Newbury Park, CA: Sage.

Ross, D. F., Dunning, D., Toglia, M. P., \& Ceci, S. (1990). The child in the eyes of the jury: Assessing mock jurors' perceptions of the child witness. Law and Human Behavior, 14, 5-23.

Ross, D. F., Read, J., \& Toglia, M. P. (Eds.). (1994). Adult eyewitness testimony. New York: Cambridge University Press.

Salthouse, T. A. (1991). Theoretical perspectives on cognitive aging. Hillsdale, NJ: Erlbaum.

Schacter, D. L., Kaszniak, A. W., Kihlstrom, J. F., \& Valdiserri, M. (1991). The relation between source memory and aging. Psychology and Aging, 6, 559-568.

Shapiro, P. N., \& Penrod, S. (1986). Meta-analysis of facial identification studies. Psychological Bulletin, 100, 139-156.

Smith, A. D., \& Winograd, E. (1978). Adult age differences in remembering faces. Developmental Psychology, 14, 443-444.

Stine, E. L., Wingfield, A., \& Poon, L. W. (1989). Speech comprehension and memory through adulthood: The roles of time and strategy. In L W. Poon, D. C. Rubin, \& B. A. Wilson (Eds.), Everyday cognition in adulthood and late life (pp. 195-221). Cambridge, MA: Cambridge University Press.

Wells, G. L., \& Loftus, E. F. (Eds.). (1984). Eyewitness testimony: psychological perspectives. Cambridge, MA: Cambridge University Press.

Wells, G. L., Turtle, J., \& Luus. C. (1989). The perceived credibility of child eyewitnesses: What happens when they use their own words? In S. Ceci, D. Ross, \& M. Toglia (Eds.), Perspectives on children's testimony (pp. 23-36). New York: Springer-Verlag.

Yarmey, A. D. (1982). Eyewitness identification and stereotypes of criminals. In A. Trankell (Ed.), Reconstructing the past (pp. 205-225). Deventer, Netherlands: Kluwer.

Yarmey, A. D. (1984). Age as a factor in eyewitness memory. In G. L. Wells \& E. F. Loftus (Eds.), Eyewitness testimony: Psychological perspectives (pp. 142-154). Cambridge, MA: Cambridge University Press.

Yarmey, A. D. (1993). Adult age and gender differences in eyewitness recall in field settings. Journal of Applied Social Psychology, 23, 1921-1932.

Yarmey, A. D., \& Jones, H. (1983). Is the psychology of eyewitness identification a matter of common sense? In S. Lloyd-Bostock \& B. R Clifford (Eds.), Evaluating witness evidence: Recent psychological research and new perspectives (pp. 13-40). Chichester: Wiley \& Sons.

Yarmey, A. D., \& Kent, J. (1980). Eyewitness identification by elderly and young adults. Law and Human Behavior, 4, 359-371. 